\title{
Sleep apnea and the nasal airway
}

\author{
Mike Fitzpatrick MD FRCPC ABSM
}

$\mathrm{N}$ asal obstruction may be important in the pathogenesis of obstructive sleep apnea (OSA). Normal subjects breathe almost exclusively via the nasal airway during quiet wakefulness and sleep (1). Snorers and patients with OSA tend to have a higher nasal resistance than normal subjects (2) and mouth breathe to a greater extent during sleep (3). If the nasal airway is occluded in normal subjects, thus forcing mouth breathing during sleep, OSA invariably ensues $(4,5)$, and this tendency to OSA is markedly increased with even partial nasal obstruction $(6,7)$. It follows that relief of nasal obstruction should significantly reduce the tendency to OSA.

Perhaps the simplest way of improving the nasal airway is to mechanically dilate the nasal valve area, the site of minimum cross-sectional area in the normal nose. Four studies have examined the effect of nasal valve dilation on OSA severity. In a double-blind, crossover design, Bahammam and colleagues (8) evaluated the efficacy of a Breathe Right (CNS Inc, USA) external nasal dilator strip in 18 patients with upper airway resistance syndrome. The use of the Breathe Right nasal strip was associated with objective improvement in anterior nasal cross-sectional area as measured by acoustic rhinometry, but not with any improvement in the apnea-hypopnea index (AHI). Snoring was not measured in that study. Among 12 nonobese patients with chronic rhinitis, Pevernagie and colleagues (9) reported no change in AHI, sleep architecture or maximum snoring intensity with the Breathe Right nasal strip, but there was a mean $33 \%$ reduction in snoring frequency associated with use of the strip. One study demonstrated a reduction in both the frequency and intensity of snoring with the Breathe Right strip in 22 of 30 subjects (10). Interestingly, in the latter study, the device was associated with reduced snoring in stages 1 and 2 of nonrapid eye movement sleep, but not in slow-wave or rapid eye movement sleep. Schonhofer and colleagues (11) evaluated the Nozovent (Scandinavian Naturals, USA) device (a plastic splint designed to sit inside the nostrils and widen the nasal valve by exerting lateral pressure on the nasal walls) in 26 patients with moderate or severe OSA. They reported no significant change in the AHI or sleep architecture with the device among the 21 patients who completed the study.

Medication can also be used to improve nasal obstruction in patients with OSA. Kerr and colleagues (12) used a randomized crossover study design to compare the effect of topical nasal decongestant in combination with stenting of the nasal vestibule with placebo (saline nose drops) in patients with OSA. The active treatment was associated with a reduced arousal frequency but no improvement in the other polysomnographic variables - sleep architecture, AHI or oxygen saturation. Similarly, the use of a nasal decongestant did not result in any improvement in either the AHI or snoring in 20 asymptomatic individuals with mild OSA (13). However, among 20 patients with allergic rhinitis, topical nasal corticosteroid was associated with a significant subjective improvement in nasal congestion and sleep quality (no objective polysomnographic measurements were made in this study) (14).

In evaluating the impact of nasal surgeries on snoring and sleep apnea, it is important to note that there have been no randomized, controlled studies in this area. Several different surgical strategies to improve the nasal airway of patients with OSA have been applied, including nasal valve reconstruction, septoplasty and turbinate mucosal reduction. The reported results of nasal surgery for OSA have been highly variable from one study to the next (15-21). In general, although nasal surgery tended to reduce subjective snoring severity in a fairly consistent manner across these studies, its effect on sleep apnea severity was highly variable. Series and colleagues (22) objectively measured both the change in nasal resistance and the change in sleep apnea severity postnasal surgery and correlated the outcome with cephalometric measurements of the upper airway. Although their two groups experienced a similar (mean $50 \%$ ) fall in nasal resistance postoperatively, the group that experienced significant improvement in sleep apnea severity postsurgery had different cephalometric characteristics (increased posterior airway space and mandibular plane to hyoid bone distance) to the nonresponders. No one has used these measurements prospectively to successfully predict the outcome of nasal surgery for OSA, however.

In summary, available literature is consistent in demonstrating an increased tendency to OSA in association with nasal obstruction, but the reported efficacy of relief of nasal obstruction as a treatment for OSA is highly variable and, in general, rather disappointing. Relatively few studies have objectively measured the efficacy of the treatment used to reduce nasal resistance, which makes it difficult to discern whether the failure to elicit improvement in snoring or OSA in those studies reflects an ineffective therapy or a bona fide treatment failure.

Division of Respiratory and Critical Care Medicine, Queen's University, Kingston, Ontario

Correspondence: Dr Mike Fitzpatrick, Division of Respiratory and Critical Care Medicine, Queen's University, 102 Stuart Street, Kingston,

Ontario K7L 3N6. Telephone 613-548-2379, fax 613-549-1459, e-mail mf19@post.queensu.ca 


\section{REFERENCES}

1. Fitzpatrick MF, Driver HS, Chatha N, Voduc N, Girard AM. Partitioning of inhaled ventilation between the nasal and oral routes during sleep in normal subjects. J Appl Physiol 2003;94:883-90.

2. Lofaso F, Coste A, d'Ortho MP, et al. Nasal obstruction as a risk factor for sleep apnoea syndrome. Eur Respir J 2000;16:639-43.

3. Gleeson K, Zwillich CW, Braier K, White DP. Breathing route during sleep. Am Rev Respir Dis 1986;134:115-20.

4. Zwillich CW, Pickett C, Hanson FN, Weil JV. Disturbed sleep and prolonged apnea during nasal obstruction in normal men. Am Rev Respir Dis 1981;124:158-60.

5. Carskadon MA, Bearpark HM, Sharkey KM, et al. Effects of menopause and nasal occlusion on breathing during sleep. Am J Respir Crit Care Med 1997;155:205-10.

6. Young T, Finn L, Palta M. Chronic nasal congestion at night is a risk factor for snoring in a population-based cohort study. Arch Intern Med 2001;161:1514-9.

7. Peppard PE, Young T, Palta M, Dempsey J, Skatrud J. Longitudinal study of moderate weight change and sleep-disordered breathing. JAMA 2000;284:3015-21

8. Bahammam AS, Tate R, Manfreda J, Kryger MH. Upper airway resistance syndrome: effect of nasal dilation, sleep stage, and sleep position. Sleep 1999;22:592-8.

9. Pevernagie D, Hamans E, Van Cauwenberge P, Pauwels R. External nasal dilation reduces snoring in chronic rhinitis patients: a randomized controlled trial. Eur Respir J 2000;15:996-1000

10. Todorova A, Schellenberg R, Hofmann HC, Dimpfel W. Effect of the external nasal dilator Breathe Right on snoring. Eur J Med Res 1998;3:367-79.

11. Schonhofer B, Franklin KA, Brunig H, Wehde H, Kohler D. Effect of nasal-valve dilation on obstructive sleep apnea. Chest 2000;118:587-90

12. Kerr P, Millar T, Buckle P, Kryger M. The importance of nasal resistance in obstructive sleep apnea syndrome. J Otolaryngol 1992;21:189-95.

13. Braver HM, Block AJ, Perri MG. Treatment for snoring. Combined weight loss, sleeping on side, and nasal spray. Chest 1995;107:1283-8.

14. Craig TJ, Teets S, Lehman EB, Chinchilli VM, Zwillich C.

Nasal congestion secondary to allergic rhinitis as a cause of sleep disturbance and daytime fatigue and the response to topical nasal corticosteroids. J Allergy Clin Immunol 1998;101:633-7.

15. Dayal VS, Phillipson EA. Nasal surgery in the management of sleep apnea. Ann Otol Rhinol Laryngol 1985;94:550-4

16. Irvine BW, Dayal VS, Phillipson EA. Sleep apnea due to nasal valve obstruction. J Otolaryngol 1984;13:37-8.

17. Dreher A, de la Chaux R, Grevers G, Kastenbauer E. [Influence of nasal obstruction on sleep-associated breathing disorders]. Laryngorhinootologie 1999;78:313-7.

18. Fairbanks DN. Snoring: surgical vs nonsurgical management. Laryngoscope 1984:94:1188-92.

19. Fairbanks DN. Predicting the effect of nasal surgery on snoring with a simple test. Ear Nose Throat J 1990;69:847.

20. Friedman M, Tanyeri H, Lim JW, Landsberg R, Vaidyanathan K, Caldarelli D. Effect of improved nasal breathing on obstructive sleep apnea. Otolaryngol Head Neck Surg 2000;122:71-4.

21. Heimer D, Scharf SM, Lieberman A, Lavie P. Sleep apnea syndrome treated by repair of deviated nasal septum. Chest 1983;84:184-5.

22. Series F, St Pierre S, Carrier G. Surgical correction of nasal obstruction in the treatment of mild sleep apnoea: importance of cephalometry in predicting outcome. Thorax 1993;48:360-3. 


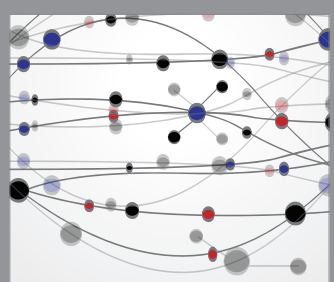

The Scientific World Journal
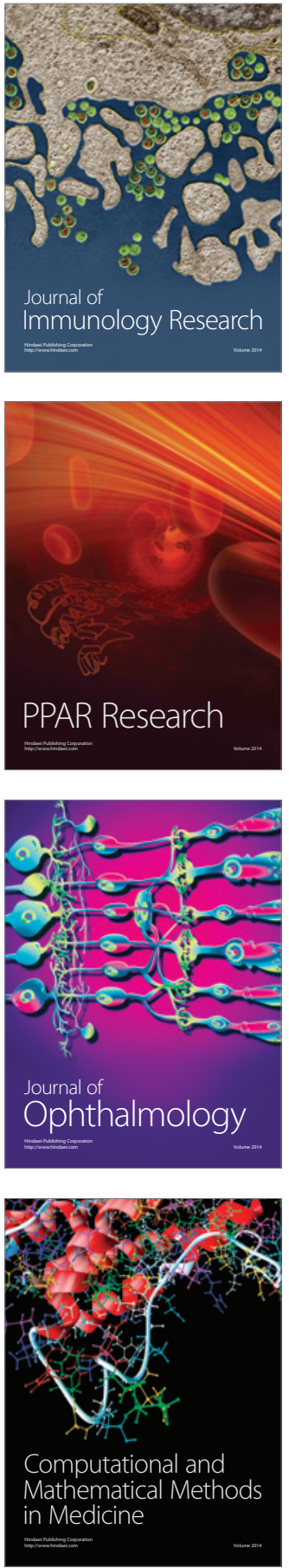

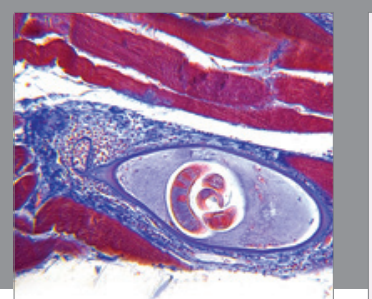

Gastroenterology Research and Practice

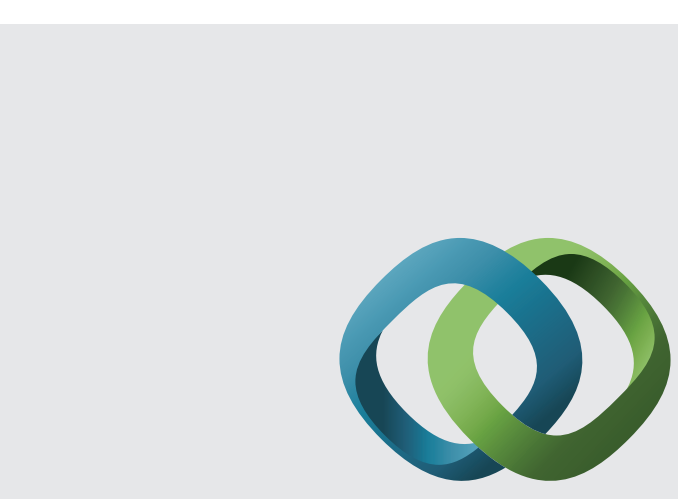

\section{Hindawi}

Submit your manuscripts at

http://www.hindawi.com
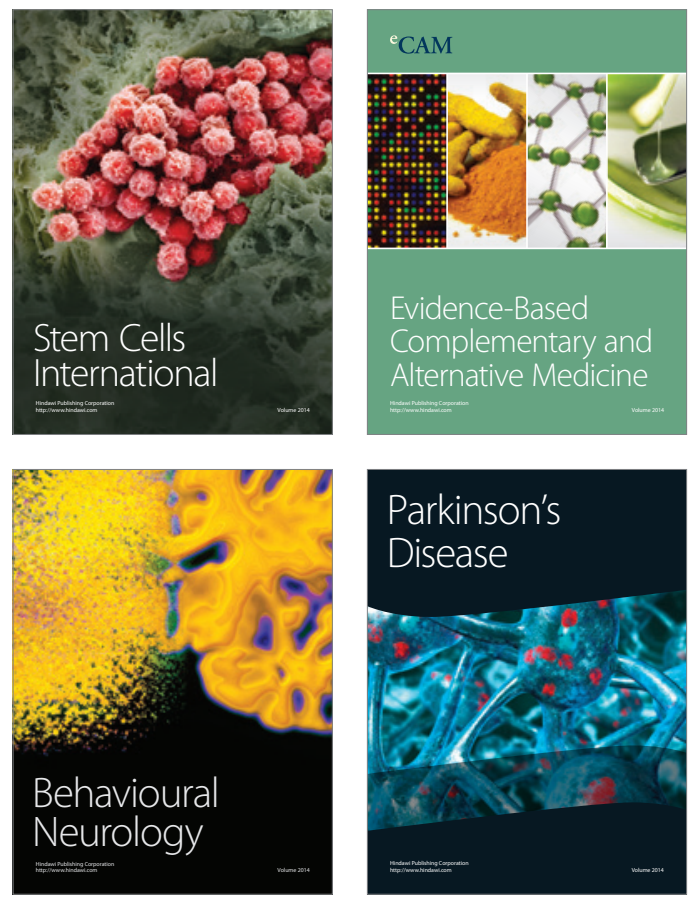
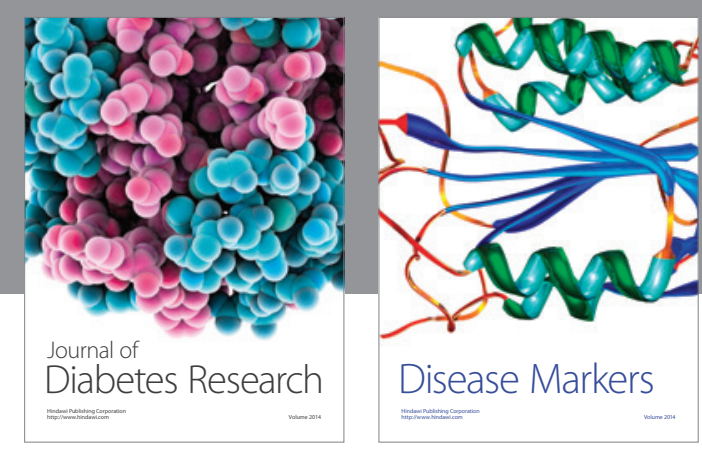

Disease Markers
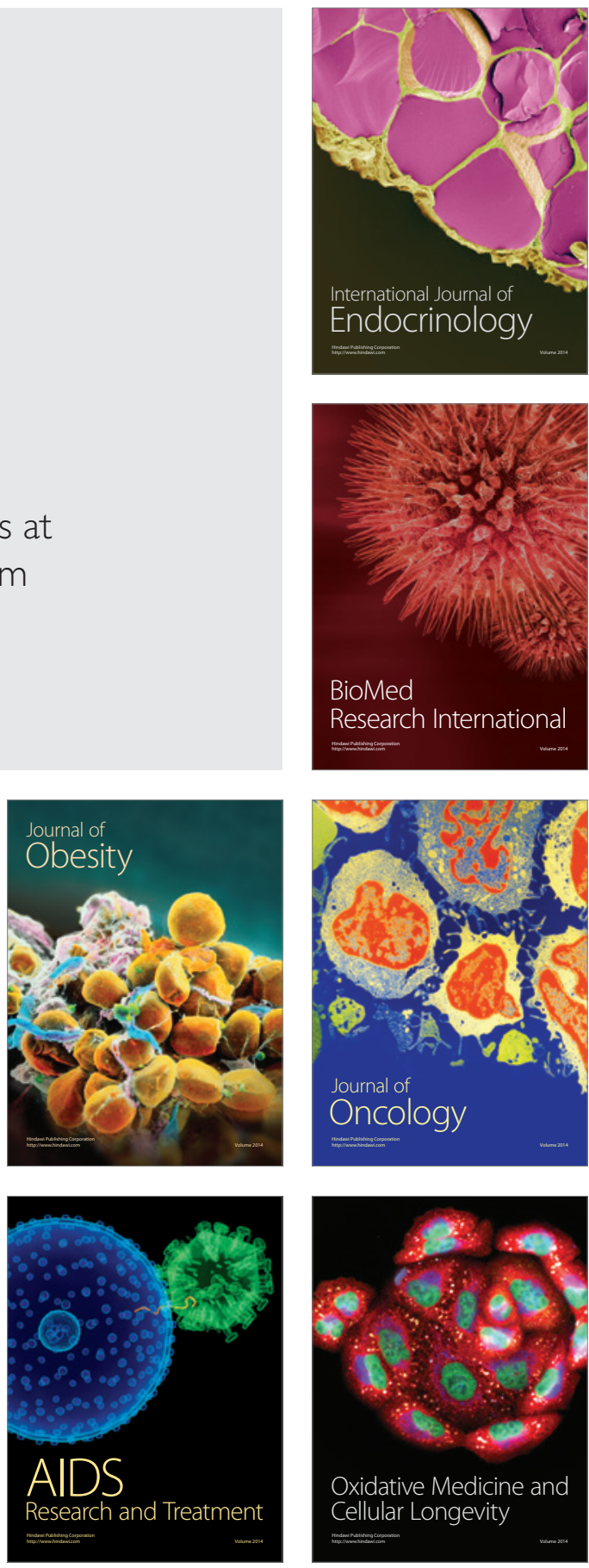